\title{
Merecido reconocimiento a un hombre comprometido con la Universidad
}

\section{Chávez Sánchez, Jorge*}

Durante este dinámico período de la historia Democrática del país, en el que he tenido el honor de ejercer una significativa responsabilidad académica, por la condición de Decano de la Facultad de Ciencias Económicas y Sociales, he sido participante activo de un conjunto de significativos acontecimientos, algunos directamente, otros de manera indirecta, de todos he podido extraer un gran número de experiencias y, vivir, en el alma, desde el corazón, muchas de ellas.

Hoy al estar frente a Ustedes, estoy inmerso en uno de esos momentos del espíritu humano, no porque nos haya correspondido organizarlo, en cumplimiento de una acertada decisión unánime, del Consejo de la Facultad de Ciencias Económicas y Sociales de Nuestra Alma Mater, la Universidad del Zulia, sino por poder agradecerles vuestra presencia en este Acto de Reconocimiento, que tan entusiastamente, hemos organizado para agradecerle a nuestro compañero y amigo, Prof. Rodrigo Cabezas, su particular y efectiva preocupación por la Universidad del Zulia, especialmente por nuestra Facultad. Que hoy, le agradece, satisfecha, de que tan carismática personalidad forme parte de ese conjunto de hombres y mujeres que forman la comunidad Universitaria, en la que los docente, somos los encargados de la formación científica de la juventud estudiosa y de la conducción administrativa de la institución, en consecuencia, somos los más responsables de su crecimiento y desarrollo, somos los constructores de su futuro.

Es para mí un verdadero honor, insisto, en poder agradecerles su asistencia a este reconocimiento, que es también, una expresión formal del proceso de enseñanza universitaria, al dejar constancia de ejemplo de la capacidad de nuestra comunidad de reconocer y con gallardía premiar a sus miembros con los aplausos del reconocimiento público.

Es la Comunidad la que con verdadero desinterés y altruismo, reconoce en uno de sus miembros las conductas meritorias, dignas de ejemplo y preñadas de ética, que han favorecido a la academia del Zulia, pero que también es reconocido el científico desempeño en una de las más importantes y determinantes estructuras que orientan las políticas de la eco- 
nomía nacional y por ende, las condiciones financieras de la administración pública y la propia calidad de vida del venezolano.

Vuestra presencia, al acompañarnos en este simbólico acto, es también un gesto de reconocimiento a nuestro amigo y distinguido Parlamentario, Prof. Rodrigo Cabezas, pero debo resaltar, la circunstancia, de que algunos de los que hoy no nos acompañan nos han expresado su apoyo y reconocimiento a los objetivo del evento y meritos de nuestro agasajado, pero motivos ajenos a su voluntad y/o compromisos previos les hizo imposible su asistencia, todos me solicitaron presentar sus saludos y congratulaciones al homenajeado, acto que realizo con enorme satisfacción y de manera pública.

¡Es una de nuestras mayores satisfacciones!, ser testigo de la solidaridad y reconocimiento que el Diputado Prof. Rodrigo Cabezas despertó en todos y cada uno de los invitados a este acto, corroborando de manera, también unánime, lo acertado de la decisión del Consejo de la Facultad, pero también llamándonos la atención el muy significativo y positivo hecho de la evolución de las emociones en el venezolano, especialmente, en este tan particular, sector que representamos los profesionales. En los que afloran, con fuerza creciente, los sentimientos de solidaridad, pertenecía y visión objetiva de un proceso, que ha transformado profundamente, por lo menos, a los grupos en el ejercicio del poder y a los objetivos y sujetos que ejercen el poder.

Sin miedo, con tranquilidad, podemos afirmar que hoy, la legitimidad del ejercicio del poder descansa en el contenido social de promoción integral de lo humano en el hombre y, de la urgente respuesta a las necesidades apremiantes para el mejoramiento de la calidad de vida del venezolano.

La legitimidad del gobierno se vincula o descansa en la efectiva protección de los derechos fundamentales del hombre, la vida; la salud, la educación y la vivienda, espacio material que determina el nivel de existencia y perspectiva material de la vida del humano.

La ciencia que pretendía explicar el hecho de la pobreza y la desigualdad de la riqueza y las oportunidades, hoy se nos devela como ideología que atenta, hasta en contra de los valores fundamentales de pertenencia a la patria. En un esquema sencillo que intentaba explicar la existencia de la pobreza como una condena perpetua para el hombre, así como la existencia de países pobres, condenados a esta situación, gracias al mismo mecanismo de una desigual distribución de la riqueza, que como hecho, era inalterable y una consecuencia "natural" de la existencia de nuestras sociedades, estábamos condenados a la miseria.

Hoy hemos retomado el verdadero camino científico, cuyo verdadero objetivo es el de la transformación de la realidad en todos sus planos, y siempre en beneficio del hombre.

La ciencia, en especial las económicos-sociales, deben orientarse al diagnostico objetivo y a la efectiva y eficiente formulación de las políticas que tengan como objeto la promoción integral del hombre. Es la solución de los problemas del crecimiento económico armónico y sustentable, un objetivo,... la lucha contra la pobreza, con una justa redistribución de la riqueza, y con el relanzamiento 
de las instituciones fundamentales de la salud y la educación....apostar a una propuesta para vencer este subdesarrollo, que más que una situación transitoria, pretendió establecerse como un final luctuoso y definitivo de nuestra sociedad.

En esa trinchera de lucha conocí a muchos, en ella conocí a Rodrigo y él, como pocos, ha sabido mantenerse fiel a esos principios, los cuales le han orientado en el excelente ejercicio de sus funciones al frente de la comisión de Finanzas de la Asamblea Nacional, pero quiero resaltar el hecho que de esos pocos, muchos, son representantes de esta nuestra Alma Mater y como Rodrigo, han sido y son ejemplos de probidad y amor por nuestra Universidad, es pues, consecuentemente, este reconocimiento a Rodrigo un reconocimiento a todos esos hombres y mujeres que han enaltecido y enaltecen la condición de Universitarios, hijos de la Universidad del Zulia.

Para quienes hemos hecho de la vida universitaria nuestra vida de desarrollo personal y de servicio a la sociedad, bien sea a través de la docencia, la investigación, la extensión y/o la conducción de la administración de la misma, sabemos que este camino está lleno de innumerables obstáculos y situaciones, muchas veces crueles y de un alto contenido de incomprensión y hasta intolerancia.

Por eso, al poder constatar el unánime reconocimiento que la actuación de Rodrigo, de apoyo y protección a las Universidades, concitó, sentí de mi parte y de los miembros de la comisión organizadora una satisfacción de reencuentro y reconciliación con lo más hermoso del espíritu humano y nos persuadimos de lo pedagógico que este acto podía llegar a ser, si lográbamos cargarlo de ese sentido de lo humano de lo poético, de lo estético que siempre esta vinculado a lo más bello y creativo del ser humano.

Rodrigo ha cumplido con su deber, ha ejercido sus funciones con acierto, dentro de las más estrictas variables de eficiencia y efectividad, ha cumplido con los principios éticos, filosóficos y científicos en los que ha creído y han guiado sus acciones, como forma de lograr el desarrollo sustentable, ecológico y con equidad social de nuestro país, siempre con un objetivo la promoción integral del hombre, en busca de una sociedad de humanos, esa era su responsabilidad y compromiso como político en funciones públicas y así, repito ha cumplido.

Pues bien todo eso, que también es la norma en muchos de nosotros, Rodrigo los realizó con la más humilde actitud, sin abandonar su aula de clases, con la permanente mirada en las partes, pese a la obligación de mirar el conjunto, con el compromiso equilibrado, pero siempre presente de impulsar los proyecto de su Alma Mater, ha sido Rodrigo, con su actitud, el ejemplo activo e histórico de la unidad, en lo diverso, del sentido de pertenencia de la comunidad universitaria, cuando se coincide en lo esencial; ...jbrindarle a los jóvenes igualdad de oportunidades de acceder a una educación universitaria de calidad y gratuita!, porque es en este punto donde debemos insistir. El presupuesto que se asigna a las Universidades Nacionales es para garantizarles a la Juventud venezolana una verdadera oportunidad de educación superior, y digo superior en todos los sentidos, la investigación, la extensión y los postgrados son mecanismos para ayudar 
y ampliar la cantidad y la cualidad de esta educación superior, es aquí donde sin claudicaciones, con gentileza y alta mira de logros, Rodrigo ha sabido demostrarnos lo sencillo y elemental de alcanzar los acuerdos necesarios para impulsar nuestra institución.

Rodrigo ha sido el compañero activo y consecuente, que ejerciendo funciones de representación popular, jamás ha distraído su responsabilidad y consecuencia para con su Universidad, ha demostrado el agradecimiento, que hoy nos alumbra reconocer, por su institución desde su formación como bachiller, la oportunidad de ejercer el magisterio de la enseñanza, en la que por la riqueza de sus experiencias profesionales y su disciplina de estudio tiene cada vez más que dar y, sus alumnos agradecen y respetan.

Es Rodrigo hoy, un símbolo para el reconocimiento a todos esos hombres y mujeres que creen firmemente en el ineludible papel transformador de la Universidad, y trabajan y luchan, incansablemente, para reactivar esa fibra cardiaca que renueve con más fuerza el latir comprometido de la Universidad por sus hijos los jóvenes venezolanos, y la creación de una ciencia y tecnología comprometida con un desarrollo armonioso y humano.

Decía El Libertador Simón Bolívar, que el pecado imperdonable del hombre era el ser malagradecido, y es que tan aberrante actitud mata en la sociedad la posibilidad del reconocimiento y consecuentemente impide la reproducción del desinterés, la vocación de servicio y sobre todo, el desprendimiento que sienta las bases de la equidad y la justicia, lo contrario a esto es el vil egoísmo.
Por eso, el sentido pedagógico de este reconocimiento, queremos al reconocerte aquí y, en funciones los méritos y la consecuencia para con la Universidad, dejar testimonio de agradecimiento y nobleza para todos los que, como tu Rodrigo, han sabido cumplir su papel, no de funcionario, sino histórico, al responder con creces a sus principios políticos y filosóficos, principios que en Venezuela han sido abandonados con escalofriante cinismo por una calificada cantidad de protagonistas a los que la historia ha pasado y pasa dolorosa factura.

Es pues este sencillo y personalizado acto, un reconocimiento sincero y afectuoso, de tus compañeros de la comunidad Universitaria, que quieren fortalecer en tu espíritu y en el propio, esa franca y decidida actitud de servicio a la Patria,... hacerlo extensivo a todos aquellos, que como tu, dan ejemplo permanente de acertado y desprendido servicio a la comunidad y permitir que tu esposa, hijos, familiares y seres queridos perciban de otros, nosotros, el afecto y cariño que te has ganado a expensas del tiempo, que debes por obligación, sustraer de ellos, a los que amando, con seguridad a veces ves con limitación de tiempo, es pues también un homenaje a tu familia.

Gracias Rodrigo, y que Dios ilumine y proteja tu futuro, en este camino cuentas con nosotros.

Gracias a Ustedes por asistir a este reconocimiento que es, también, reitero, un reconocimiento a los hombres y mujeres que hoy luchan por una mejor y más justa Venezuela.

Gracias. 